\title{
The Treatment of Gastric Mucosa-Associated Lymphoid Tissue Lymphoma using Radiotherapy
}

\section{Introduction}

Gastric mucosa-associated lymphoid tissue lymphoma (MALT lymphoma) is the second-most common subtype of non-Hodgkin's lymphoma, the first being diffuse large B-cell lymphoma (DLBCL). ${ }^{[1]}$ The most common causative organism for gastric MALT lymphoma is Helicobacter pylori. $80 \%$ of Stage I and $45 \%-56 \%$ of Stage II patients achieve remission after $H$. pylori eradication. ${ }^{[2-4]}$ The treatment options for refractory MALT lymphoma include chemotherapy, radiotherapy, surgery, and immunotherapy. Only a few studies have reported the efficacy and the safety of radiotherapy in the treatment of gastric MALT lymphoma. ${ }^{[5]}$ We report a patient with refractory gastric MALT lymphoma who was treated effectively and safely with advanced radiation technique. The patient is on follow-up with a disease-free survival (DFS) of 12 months duration.

\section{Case Report}

A 60-year-old male with no known comorbidities, who was an ex-smoker, was evaluated for dyspepsia of 1-year duration. There was no history of vomiting, loss of weight, hematemesis, melena, cough, headache, bone pain, or jaundice. The patient was hemodynamically stable. There were no signs of pallor, jaundice, or supraclavicular lymphadenopathy. On examination per abdomen, it was soft with no signs of ascites, hepatomegaly, or any evidence of portal hypertension. Per rectal examination was unremarkable.

\section{Question 1}

What is the provisional diagnosis from the above clinical presentation?

\footnotetext{
This is an open access journal, and articles are distributed under the terms of the Creative Commons Attribution-NonCommercial-ShareAlike 4.0 License, which allows others to remix, tweak, and build upon the work non-commercially, as long as appropriate credit is given and the new creations are licensed under the identical terms.
}

For reprints contact: WKHLRPMedknow_reprints@wolterskluwer.com
Answer

Primary gastric pathology probably nonmetastatic gastric carcinoma.

Upper gastrointestinal (UGI) endoscopy revealed a circumferential thickening with erythematous, edematous, friable mucosa with multiple superficial ulcerations seen involving the middle and the distal body, incisura, antrum, and pylorus of the stomach with poor distension and absent peristalsis. Computerized tomography (CT) showed a circumferential wall thickening with the loss of mural stratification involving the lesser and the greater curvature of the stomach extending into the pyloric antrum with enlarged perigastric and peripyloric lymph nodes noted. Endoscopic biopsy was suggestive of marginal zone lymphoma.

Immunohistochemistry revealed positivity for LCA, CD20, BCL2, CD3, CD 10, BCL6, and CD5. CD23, Cyclin D1 were negative and KI 67 was $20 \%$. Bone marrow aspiration and bone marrow biopsy were negative. Positron emission tomography (PET CT) revealed circumferential wall thickening with loss of mural stratification involving the lesser and the greater curvature of stomach extending into the pyloric antrum measuring 2.3 $\mathrm{cm}$ with standard uptake value of 9.8 and enlarged perigastric and peripyloric nodes. Hence, the patient was diagnosed with a case of gastric MALT lymphoma stage II E (Ann Arbor staging system).

\section{Question 2}

What is the first-line management of gastric MALT Lymphoma?

\section{Answer \\ H. pylori eradication.}

The patient was started on $H$. pylori eradication regimen for 2 weeks. The

\footnotetext{
How to cite this article: Nagarajan A, Sakthivelu A, John A, Ravichandar R. The treatment of gastric mucosa-associated lymphoid tissue lymphoma using radiotherapy. Indian J Med Paediatr Oncol 2020;41:559-61.
}

\author{
Aswin Nagarajan', \\ Arun Sakthivelu', \\ Alexander John', \\ Ramya Ravichandar ${ }^{2}$ \\ ${ }^{\prime}$ Department of Radiation \\ Oncology, Cancer Institute, \\ Chennai, Tamil Nadu, India, \\ ${ }^{2}$ Department of Pharmacology, \\ Sree Balaji Medical College and \\ Hospital, Chennai, Tamil Nadu, \\ India
}

Submitted: 26-Apr-2020 Accepted in Revised Form: 17-Jul-2020

Published: 29-Aug-2020 Address for correspondence:
Dr. Aswin Nagarajan, 38,
Sardar Patel Road, Adyar,
Chennai - 600 020, Tamil Nadu,
India.
E-mail: ashwinnagu@rediffmail.
com

Access this article online

Website: www.ijmpo.org

DOI: 10.4103/ijmpo.ijmpo_196_20 Quick Response Code:

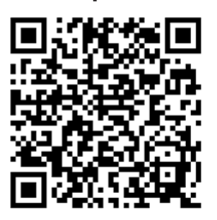


patient had a very minimal improvement in his symptom and the UGI endoscopy revealed a stable disease. After discussion in the multidisciplinary board, he was planned for radical radiotherapy. He received radiotherapy using intensity-modulated radiotherapy (IMRT) technique [Figure 1] up to a total dose of 3060cGy (180cGy/ day $\times 17$ fractions). The patient completed the treatment without much morbidity. The mean dose to both the kidneys was $10 \mathrm{~Gy}$, the mean dose to the liver was 18 Gy, and the maximum dose to the spinal cord was $21 \mathrm{~Gy}$ [Figures 2 and 3].

\section{Question 3}

What are the other malignancies associated with $H$. pylori infection?

\section{Answer}

DLBCL and gastric adenocarcinoma.

Relook UGI endoscopy after 4 months was suggestive of inflammatory mucosa and PET CT showed a complete metabolic response. The patient had been kept under follow-up with a DFS of 12 months with periodic

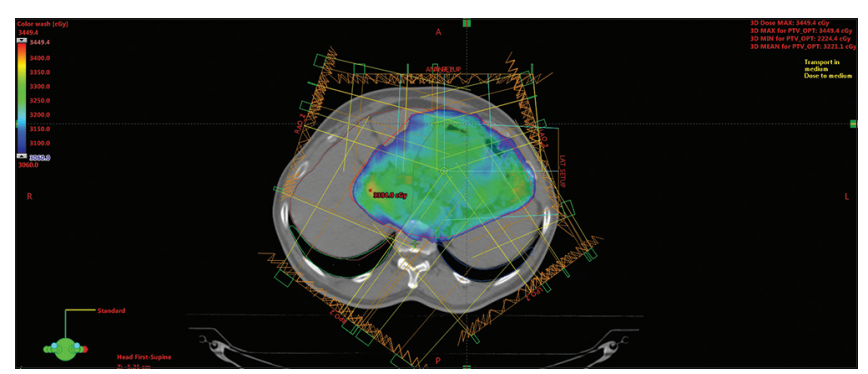

Figure 1: Shows the dose distribution in intensity-modulated radiotherapy technique endoscopies to rule out disease recurrence as well as to know the occurrence of other malignancies associated with $H$. pylori (diffuse large B-cell lymphoma and gastric adenocarcinoma).

\section{Discussion}

As mentioned earlier, the first-line treatment for gastric MALT lymphoma is $H$. pylori eradication. Radiotherapy, chemotherapy, surgery, and immunotherapy are considered if the disease is refractory to the primary treatment. Since there are no randomized trials performed comparing the different treatment modalities, due to treatment heterogeneity and small sample size, the treatment of gastric MALT lymphoma, refractory to $H$. pylori eradication, is not clear.

Pooled data analysis showed a slightly better response rate to radiotherapy when compared to chemotherapy in refractory setting. ${ }^{[4]}$ The general consensus is that radiotherapy is reserved for localized disease and chemotherapy for advanced disease. ${ }^{[6]}$ Since our patient had a localized disease and was refractory to the primary treatment modality, radiotherapy was contemplated to which the patient had a complete response.

The target volume for radiotherapy was the whole abdomen followed by a boost dose to the stomach and the perigastric lymph nodes in the past. ${ }^{[7]}$ As time evolved, it has been found that localized gastric MALT lymphoma was confined to the gastric wall and the perigastric lymph nodes, and hence, the target volume was reduced to the stomach and the perigastric lymph nodes. ${ }^{[8]}$ In our patient, the target volume for radiotherapy was confined only to the stomach and the involved lymph nodes.

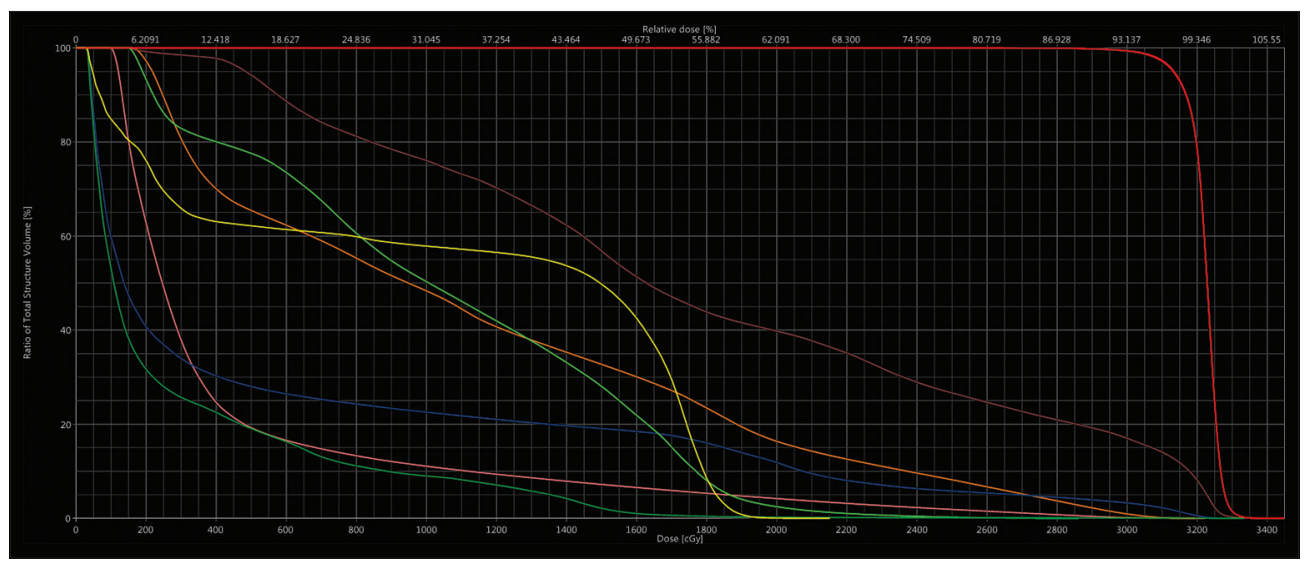

Figure 2: Show the dose-volume histogram

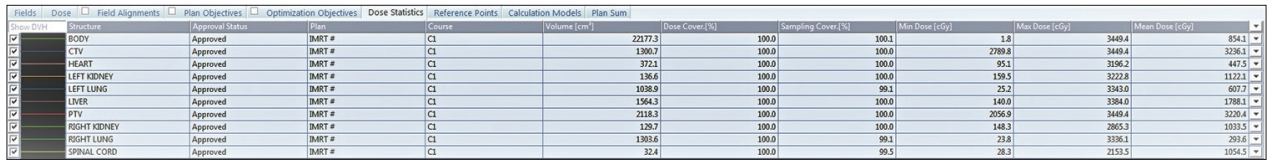

Figure 3: Shows the dose statistics of the organsc 
Tomita et al. evaluated the efficacy of radiation therapy in early-stage MALT lymphoma and found that 25-30 Gy radiation is effective for local control ${ }^{[9]}$ Pinnix et al. showed that IMRT technique is associated with complete response even with reduced dose up to 24 Gy. ${ }^{[10]}$ However, our patient had received radiotherapy of a total dose of $30 \mathrm{~Gy}$ by IMRT technique with good local control and without much morbidity.

Nam et al. evaluated 41 patients with low-grade lymphoma and found that three patients at follow-up developed secondary malignancies (2 DLBCL and 1 gastric adenocarcinoma) who were salvaged by chemotherapy and surgery, respectively. ${ }^{[11]}$ Although our patient had a complete response with radiotherapy, he has been followed up with endoscopy as well as metabolic imaging (PET CT) to rule out the recurrence as well as the secondary malignancies.

\section{Conclusion}

Although $H$. pylori eradication is the main stay of treatment in gastric MALT lymphoma, radiotherapy is an effective option for refractory MALT lymphoma. Using advanced radiation techniques such as IMRT, the dose to the surrounding organs can be minimized. Although some studies show that the total dose reduction can be done with IMRT technique, this has to be explored by larger studies. The patient has to be kept under constant follow-up with endoscopy, biopsy (if needed), and imaging to rule out the disease recurrence as well as to find out the occurrence of secondary malignancies which can be salvaged effectively if diagnosed at an early stage.

\section{Declaration of patient consent}

The authors certify that they have obtained all appropriate patient consent forms. In the form the patient(s) has/have given his/her/their consent for his/her/their images and other clinical information to be reported in the journal. The patients understand that their names and initials will not be published and due efforts will be made to conceal their identity, but anonymity cannot be guaranteed.

\section{Financial support and sponsorship}

Nil.

\section{Conflicts of interest}

There are no conflicts of interest.

\section{References}

1. Marshall BJ, Windsor HM. The relation of Helicobacter pylori to gastric adenocarcinoma and lymphoma: Pathophysiology, epidemiology, screening, clinical presentation, treatment, and prevention. Med Clin North Am 2005;89:313-44, viii.

2. Nakamura S, Sugiyama $T$, Matsumoto $T$, Iijima $K$, Ono $S$, Tajika $\mathrm{M}$, et al. Long-term clinical outcome of gastric MALT lymphoma after eradication of Helicobacter pylori: A multicentre cohort follow-up study of 420 patients in Japan. Gut 2012;61:507-13.

3. Ahmad A, Govil Y, Frank BB. Gastric mucosa-associated lymphoid tissue lymphoma. Am J Gastroenterol 2003;98:975-86.

4. Zullo A, Hassan C, Cristofari F, Andriani A, De Francesco V, Ierardi E, et al. Effects of Helicobacter pylori eradication on early stage gastric mucosa-associated lymphoid tissue lymphoma. Clin Gastroenterol Hepatol 2010;8:105-10.

5. Park HC, Park W, Hahn JS, Kim CB, Lee YC, Noh JK, et al. Low grade MALT lymphoma of the stomach: Treatment outcome with radiotherapy alone. Yonsei Med J 2002;43:601-6.

6. Ruskoné-Fourmestraux A, Fischbach W, Aleman BM, Boot H, Du MQ, Megraud F, et al. EGILS consensus report. Gastric extranodal marginal zone B-cell lymphoma of MALT. Gut 2011;60:747-58.

7. Burgers JM, Taal BG, van Heerde P, Somers R, den Hartog Jager FC, Hart AA. Treatment results of primary stage I and II non-Hodgkin's lymphoma of the stomach. Radiother Oncol 1988;11:319-26.

8. Isaacson PG. Gastric MALT lymphoma: From concept to cure. Ann Oncol 1999;10:637-45.

9. Tomita N, Kodaira T, Tachibana H, Nakamura T, Mizoguchi N, Takada A. Favorable outcomes of radiotherapy for early-stage mucosa-associated lymphoid tissue lymphoma. Radiother Oncol 2009;90:231-5.

10. Pinnix CC, Gunther JR, Milgrom SA, Cruz Chamorro RJ, Medeiros LJ, Khoury JD, et al. Outcomes after reduced-dose intensity modulated radiation therapy for gastric mucosa-associated lymphoid tissue (MALT) lymphoma. Int J Radiat Oncol Biol Phys 2019;104:447-55.

11. Nam TK, Ahn JS, Choi YD, Jeong JU, Kim YH, Yoon MS, et al. The role of radiotherapy in the treatment of gastric mucosa-associated lymphoid tissue lymphoma. Cancer Res Treat 2014;46:33-40. 